\title{
Virus infection induces neuronal apoptosis: A comparison with trophic factor withdrawal
}

\author{
Timothy E. Allsopp ${ }^{1,3}$, Martina F. Scallan ${ }^{1,4}$, Alun Williams ${ }^{2}$ \\ and John K. Fazakerley ${ }^{1,5}$ \\ 1 Department of Veterinary Pathology, University of Edinburgh, EH9 1QH, UK
2 Institute for Animal Health, BBSRC/MRC Neuopathogenesis Unit, Edinburgh,
EH9 3JF, UK
3 Present address: Fujisawa Institute of Neuroscience, Department of
Pharmacology, University of Edinburgh, UK
${ }^{4}$ Present address: Department of Microbiology, University College Cork, Cork,
Ireland
5 Corresponding author: JK Fazakerley, tel: 01316506160 ; fax: 01316506160 ;
e-mail: John.Fazakerley@ed.ac.uk
}

Received 29.5.97; revised 10.7.97; accepted 30.7.97

Edited by R.A.Knight

\begin{abstract}
Multicellular organisms can employ a number of defences to combat viral replication, the most dramatic being implementation of a cell autonomous apoptotic process. The overall cost to the viability of an organism of losing infected cells by apoptosis may be small if the dying cells can be substituted. In contrast, suicide of irreplaceable cells such as highly specialised neurons may have a more dramatic, even fatal consequence. Previous in vitro approaches to understanding whether neurotropic viruses cause neurons to apoptose have utilised transformed cell lines. These are not in the appropriate state of differentiation to provide an accurate indication of events in vivo. We have chosen to characterise the ability of a model CNS disease-causing virus, Semliki Forest virus (SFV), to infect and trigger apoptosis in primary cultures of nerve growth factor (NGF)-dependent sensory neurons. These cells are known to die when deprived of NGF and constitute a useful indicator of apoptosis. We observe that infection causes cell death which bears the morphological hallmarks of apoptosis, this occurs even in the present of survival promoting NGF and is concomitant with new virus production. Using the TUNEL (transferase dUTP nick end labelling) technique we show that SFV-induced apoptosis involves DNA fragmentation and requires caspase (CED-3/ICE cysteine protease) activation, as does apoptosis induced by NGF-deprivation. Extensive areas of apoptosis, as defined using a combination of ultrastructural analysis and TUNEL occur in infected neonatal mouse brains. The novel evidence that infection of primary neurons with SFV induces apoptosis with activation of one or more caspases defines a system for the further anlaysis of apoptosis regulation in physiologically relevant neurons.
\end{abstract}

Keywords: neuron; alphavirus; apoptosis; Semliki Forest virus; nerve growth factor; programmed cell death; primary culture

\begin{abstract}
Abbreviations: NGF, nerve growth factor; CNS, central nervous system; SFV, Semliki Forest virus; MOI, multiplicity of infection; PFU, plaque forming units; TUNEL, terminal transferase dUTP nick end labelling; DMSO, dimethyl sulphoxide; Ac-DEVD-cho, Ac-Asp-Glu-Val-Asp-aldehyde; zVADfmk, benzyloxycarbonyl-Val-Ala-Asp-fluoromethylketone; leupeptin, Ac-Leu-Leu-Arg-aldehyde; TLCK, N-tosyllysine chloromethylketone; PARP, poly ADP-ribose polymerase
\end{abstract}

\section{Introduction}

Programmed cell death is an evolutionary conserved mechanism for the discrete removal of superfluous, damaged and non-functional cells from multicellular organisms during development and in disease (Steller, 1995; Thompson, 1995). The stereotyped series of morphological changes (apoptosis) is regulated and effected by specific proteins, some of which are expressed uniquely in order for cells to die. Death can be triggered by any one of several diverse physiological and pathological types of stimuli. These include hormone, neurotransmitter and growth factor exposure; survival factor deprivation; loss of cell or matrix interaction; heat shock; and exposure to bacterial toxins, oxidants, UV-irradiation, chemotherapeutiuc drugs and other environmental toxins. A substantial body of evidence also indicates that apoptosis may be a common cellular response to viral infection (White, 1996).

Many RNA and DNA viruses with host ranges as diverse as insects and mammals have been shown to trigger apoptosis following infection (Levine et al, 1993; Clem et al, 1991; Rao et al, 1992; Gillet and Brun, 1996). Independent engagement of apoptosis might be considered as a primitive anti-viral defence employed by multicellular organisms to curtail virus replication and minimise virus spread. That the apoptotic response is an effective anti-viral strategy is demonstrated by the presence in a number of viruses, notably DNA viruses of anti-apoptotic genes. These not only inhibit endogenous apoptosis in response to infection, but can in some cases function to prevent killing by virus-specific cytotoxic T-cells. In contrast, it can also be argued that in some cases apoptosis induction following infection might be beneficial enabling virus spread, as has been suggested for the human immunodeficiency virus (Strack et al, 1996).

Virus-encoded anti-death genes can be categorised according to how they regulate or inhibit apoptosis. Several different viral proteins inhibit apoptosis via a direct interaction with the tumour suppressor protein p53 (Rao et al, 1992). Other viral proteins inhibit apoptosis by acting as functional bcl-2 homologues (Oltvai et al, 1993; Keifer et al, 1995; White, 1996). Other viral proteins act as irreversible inhibitors of the CED-3/ICE related caspases, 
the executioners of death. Known virus-encoded caspase inhibitors are the serpins of pox viruses and the p35 protein of baculovirus. Recent evidence indicates that herpesviruses and poxviruses also contain a distinct class of anti-apoptotic genes which function to inhibit caspase activation by death domain receptors of the tumour necrosis factor receptor superfamily (Bertin et al, 1997; Thome et al, 1997).

Several studies have shown that virulent strains of neurotropic viruses can induce apoptosis of neural cells not only in vitro but also in vivo following infection and that the phenomenon might therefore contribute significantly to a disease state and host mortality (Lewis et al, 1996; Despres et al, 1996; Pekosz et al, 1996; Ubol et al, 1996). Semliki Forest virus, an alphavirus of the Togaviridae is a model for studies on the cell and molecular pathology of virus-induced CNS disease. Mice of all ages infected with the virulent L10 strain of the virus develop a fatal encephalitis with widespread cell destruction. Neonatal mice infected with the avirulent $A 7(74)$ strain also die due to a lethal encephalitis, but mice older than 2 weeks and infected with the $A 7(74)$ strain develop a subacute encephalitis with demyelination (Fazakerley and Webb 1987; Fazakerley et al, 1993). All previous in vitro studies on virus induced death have utilised neuroblastoma or transformed cell lines that have been virally infected prior to, or soon after being rapidly differentiated. Although these studies have provided valuable information on possible viral and cellular components involved in apoptosis induction (Despres et al, 1996; Ubol et al, 1996; Lin et al, 1995; Pekosz et al, 1996), there is substantial evidence indicating that the outcome of neuronal infection with a number of viruses is intricately linked to the neuronal differentiation state (Swoveland and Johnson, 1989; Sharpe et al, 1990; Oliver et al, 1997). As it is also known that neuronal susceptibility to apoptosis changes during development, it is therefore important to characterise the death response to infection in neuronal cells other than neuroblastomas and at precisely defined stages of differentiation.

We have established a tissue culture model consisting of post-mitotic, differentiated, embryonic mouse sensory neurons. The neurons require NGF for their survival in vivo and in vitro, and NGF deprivation of these cells rapidly induces apoptosis. Previous studies using mixed explant cultures of sensory neurons and satellite cells have shown that the related alphavirus, Sindbis, kills by an apoptotic mechanism (Levine et al, 1993). We have studied dissociated, rather than explant, cultures of sensory neurons in order to analyze the direct consquence of SFV infection on patho-physiologically relevant neurons. We show that SFV infection induces these neurons to die rapidly, even in the presence of NGF, with the morphology of apoptosis, and a requirement for caspase activity. Ultrastructural and TUNEL analysis also reveals apoptotic neural cells in immature SFV-infected mouse brains. Thus we present novel evidence that primary neurons undergo apoptosis following alphavirus infection and that the process requires the function of one or more caspases.

\section{Results}

\section{Morphological comparison of virus- and NGF deprivation-induced death}

At an early stage of their in vivo differentiation neurons of the trigeminal cranial sensory ganglion undergo naturally occurring cell death, a process bearing the features of apoptosis. The amount of cell death in vivo is regulated by a limiting supply of target field derived NGF. Survival in culture of such neurons taken from mouse embryos on day 14 (E14) could be maintained by exogenous addition of NGF $(2-4 \mathrm{ng} / \mathrm{ml})$ (Figure 1A). Subsequent deprivation from NGF by incubation in NGF-free medium induced greater than $90 \%$ of neurons to die within $48 \mathrm{~h}$ (Figure 1A). Addition of SFV A7(74) to cultures maintained in the presence of NGF resulted in cell death. In order to ensure that the virus preparation contained no other factors likely to induce cell death, the virus preparation had been purified from the supernatant of infected BHK cells by centrifugation through a sucrose gradient and further washed by re-suspension and centrifugation. The majority of virusinfected cells were dead within $24 \mathrm{~h}$ when a multiplicity of infection (MOI) of 50 (50 plaque forming units/cell) was used to infect the neurons, but significant numbers of surviving neurons remained at $48 \mathrm{~h}$ following application of virus at MOI of 5 and 0.5 (Figure $1 \mathrm{~A}$ ). At an $\mathrm{MOI}$ of 5 there was clearly some death after $24 \mathrm{~h}$ compared with that observed for control cultures maintained in NGF alone (approximately $75 \%$ and $95 \%$ respectively). The amount of cell death in the $\mathrm{MOI}$ of 5 infected cultures then increased over the ensuing $24 \mathrm{~h}$ so that by $48 \mathrm{~h}$ post-infection greater than $60 \%$ of the cells were dead. As this rate of decline in viability was suitable for cellular analysis of the mode of death we chose to study cultures infected with a standard $\mathrm{MOI}$ of 5 . As assessed by immunofluorescent staining for viral proteins, at a $\mathrm{MOI}$ of 5 not all neurons were infected by $24 \mathrm{~h}$ (Figure 1B).

To further characterise the time-course and type of cell death initiated by infection cultures were either grown continuously with NGF, grown with NGF and infected $(\mathrm{MOI}=5)$ with either the $\mathrm{A} 7(74)$ or $\mathrm{L} 10$ strains of SFV, or grown initially with NGF and then deprived. For each of the different experimental conditions the same population of cells was then assessed every $24 \mathrm{~h}$ and the number of viable neurons quantified (Figure 2A). Neurons grown initially with NGF and then subsequently deprived were nearly all dead by 3 days whereas neurons grown continuously with NGF survived in large numbers for up to 5 days. However, over this time approximately $40 \%$ of the neurons died in these cultures indicating that a supplement of NGF alone was insufficient to keep all the neurons viable for long periods. This decline in viability in the presence of NGF is strikingly different from that observed for cells infected with either the A7(74) or L10 strains of SFV. Both virus strains were equally effective in killing greater than $90 \%$ of the neurons within 3 days despite the presence of NGF. Virus replication in neurons was analyzed by titration of harvested culture supernatants using a plaque assay on BHK cells. A 100- (A7(74)) and 300-fold (L10) increase in detectable virus over the quantity of input virus was observed $72 \mathrm{~h}$ after infection. This finding is consistent with the in vivo studies showing replication of 
A

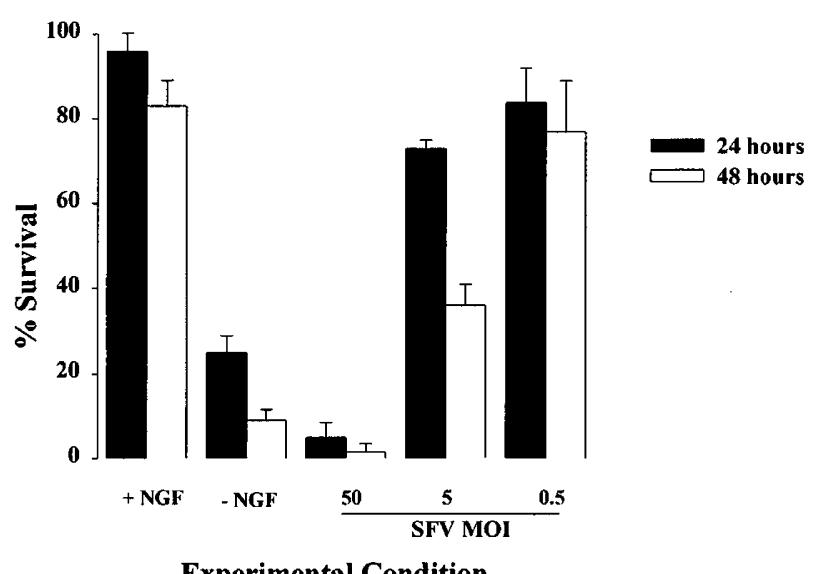

Experimental Condition

B

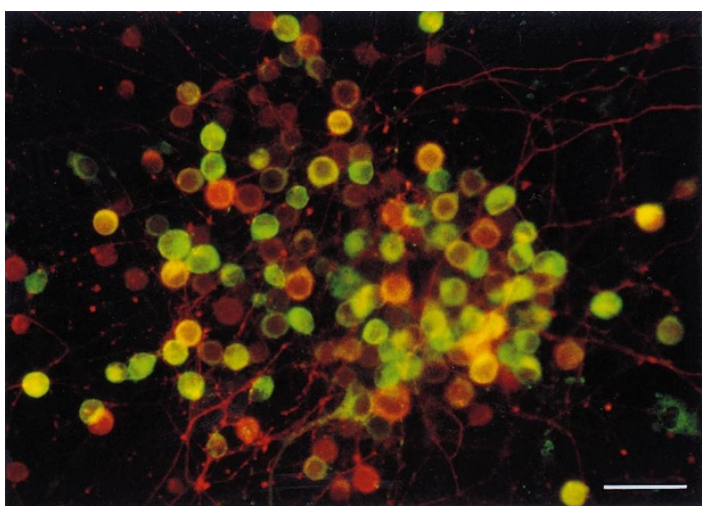

Figure 1 Embryonic mouse sensory neurons support Semliki Forest virus (SFV) replication, but die rapidly as a consequence of infection. Primary cultures of NGF-dependent trigeminal neurons were infected with SFV A7(74) at different multiplicity of infections (MOI) and the number of viable neurons counted after $24 \mathrm{~h}(\boldsymbol{\square})$ and $48 \mathrm{~h}(\square)(\mathbf{A})$. Counts are expressed as a percentage of the initial average number of neurons per dish prior to infection. Counts are compared with the percentage survival of uninfected neurons either grown continuously with NGF $(4 \mathrm{ng} / \mathrm{ml})$ or grown initially with NGF and then deprived for $48 \mathrm{~h}$. Data is presented as the mean ( + S.D.) from 2 experiments $(n=8)$. Prior to cell death neurons express viral proteins (B). Immunofluorescence reveals viral protein and neurofilament co-expression in the somas of some, but not all neurons $30 \mathrm{~h}$ following infection $(\mathrm{MOI}=5$ ). Neuronal nuclei are not stained. Green, virus proteins only; yellow, virus proteins and neurofilaments. A significant number of neurons appear uninfected or are not expressing viral proteins, but express neurofilaments in their somas and neurites (red). Scale bar $=200 \mu \mathrm{ms}$

these virus strains in, and the associated destruction of, neonatal neurons (Fazakerley et al, 1993).

When small cohorts of cells exposed to either NGF deprivation or virus were visualised over time it became apparent that cells were indeed dying with different rates, but with very similar morphologies (Figure 2B). As has been described previously for neurons apoptosing in response to trophic factor deprivation (Allsopp et al, 1993), the cytoplasm of both NGF-deprived and virusexposed neurons darkened and the neurites fragmented. In contrast, neurons exposed to NGF retained a phase-bright, spherical soma with extensive neuritic outgrowth. When viewed with higher resolution the characteristic darkening and fragmentation was accompanied by extensive membrane activity and pitting (Figure $2 \mathrm{C}$ ), phenomena not observed for the quiescent membrane of neurons grown in NGF. Thus SFV-infected neurons were rapidly dying with morphologies that were consistent with apoptosis.

\section{Apoptosis accompanies virus infection in brains}

To determine if neural cell death following SFV infection in vivo also possessed the morphological features of apoptosis, neonatal mice were infected intranasally with the $A 7(74)$ strain of the virus and at $48 \mathrm{~h}$ brains were removed, fixed and processed for electron microscopy. Careful analysis revealed several lesioned areas containing many cells with the characteristics of apoptosis; typically these cells were electron dense with a vesicular cytoplasm and an irregular shaped nucleus (Figure 3) containing clumps of condensed chromatin. Some dying cells clearly displayed vesicular, virus replication structures known as cytopathic vacuoles, as described by Pathak and Webb (1978) (magnified inset Figure 3).

\section{DNA breaks occur concomitant with infection}

As cleavage of DNA into large or small, oligonucleosomalsized fragments is regularly detected in cells dying by apoptosis (Peitsch et al, 1994) we analyzed the virus induced cell death in the neuronal cultures for indications of DNA degradation. Due to the low density of cells biochemical analysis of DNA fragmentation using agarose gel electrophoresis was precluded. We therefore monitored nuclear DNA changes using antibody detection of terminal transferase-mediated incorporation of labelled deoxyUTP nucleotides into the open ends of DNA strands (TUNEL method) (Gavrielli et al, 1992). Neuronal cultures were infected with SFV then subsequently fixed and processed for the TUNEL procedure. In order to phenotype the potential TUNEL positive cells the preparations were also immunofluorescently stained using the RT97 phosphorylated neurofilament reactive antibody. Numerous TUNEL positive nuclei were associated with the large scale cytopathology observed $36 \mathrm{~h}$ after infection (Figure 4A; green). Some clearly consisted of fragmenting nuclei (arrowheads Figure 4A). Double staining revealed that a significant number of these TUNEL positive nuclei belonged to neurons (Figure 4B; red neurofilament stain) although the extent of this could not be fully appreciated as not all neurons were stained using the RT97 antibody. Double staining also indicated that not all the neurons were TUNEL reactive (arrows Figure 4b). Control TUNEL reactions in which the terminal transferase or labelled nucleotide were omitted, or where the reaction was performed on NGF-treated uninfected cells, all yielded negative results (data not shown).

Using a double immunocytochemical detection procedure of TUNEL and anti-SFV antibodies, apoptotic and infected cells were observed in the brains of infected (Figure 4D) but not in uninfected neonatal (post-natal day 4 (P4)) mice (Figure 4C). Inoculating virus intranasally led to 
A

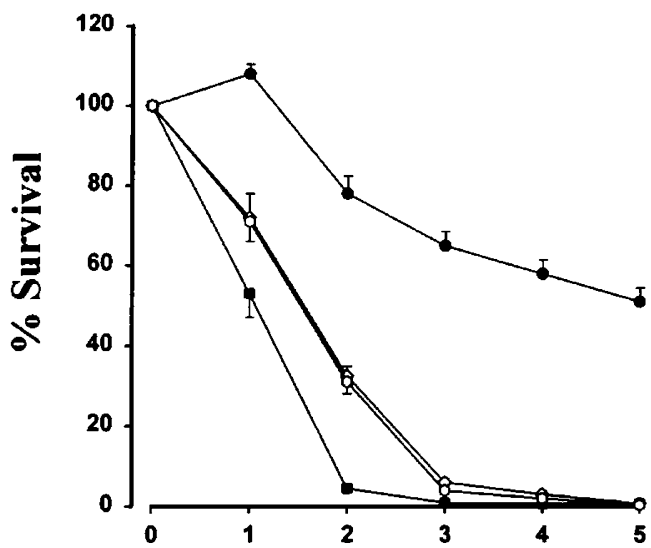

Days Post Treatment

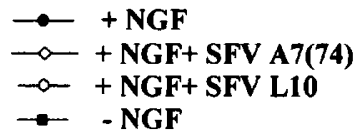

C

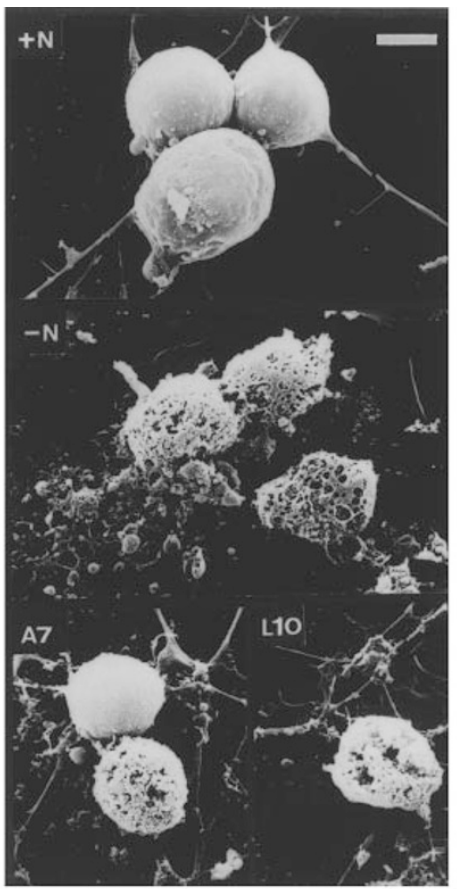

60 hrs

B

$0 \mathrm{hrs}$

30 hrs
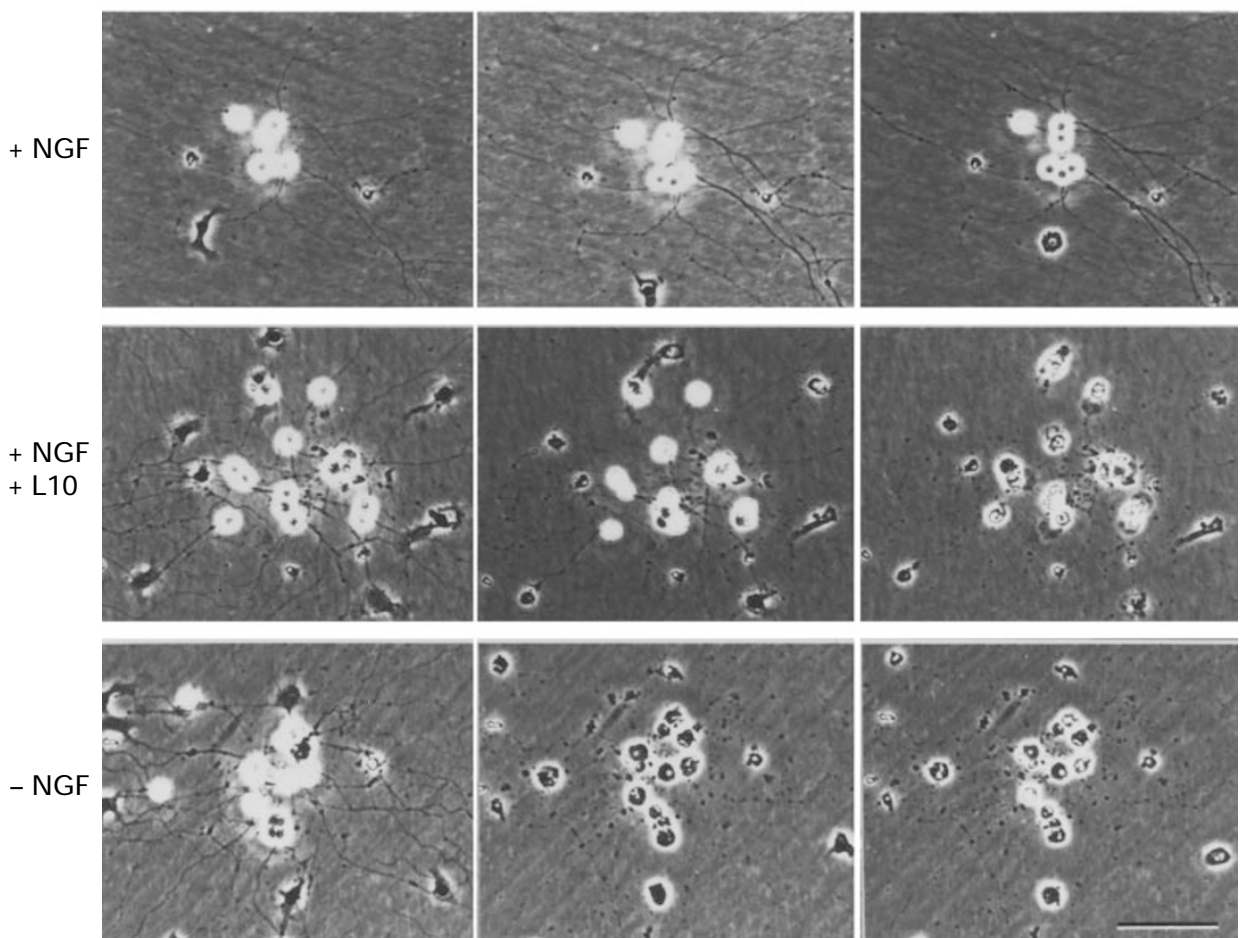

Figure 2 Neurons cultured in the presence of NGF die with the morphology of apoptosis following SFV infection. (A) Low density cultures were either grown continuously with NGF $(\mathbf{O})$, grown initially with NGF and then deprived $(\mathbf{\square})$, or grown with NGF and infected (MOI=5) with either SFV A7(74) $(\diamond)$ or SFV L10 (O). The number of viable neurons was counted every $24 \mathrm{~h}$ for 5 days and the counts expressed as described in Figure 1. Data presented is the mean ( \pm S.E.M.) of 6 experiments $(n=24)$. Neurons grown in the presence or absence of NGF, or infected with SFV L10 as described above were monitored over time using phase contrast microscopy (B) or analyzed $30 \mathrm{~h}$ after infection by scanning electron microscopy (C). Sensory neurons possess uniformly small, spherical somas and long intact neurites and remain viable when grown in the presence of NGF for prolonged periods (+NGF). When deprived of NGF ( - NGF) the neurons rapidly lose their phase brightness, shrink and fragment. A similar morphological transition occurs when the neurons are infected with SFV (+NGF, +L10; MOI=5), although the shrinkage and fragmentation takes longer to be initiated (Numbers indicate time (h) from NGF deprivation or infection). Scanning electron microscope analysis reveals extensive membrane pitting when neurons are deprived of NGF or infected with SFV $(A 7(74)$ or $L 10 ; M O I=5)$. Scale bar: $(B)=200 \mu m s ;(C)=20 \mu m s$ 


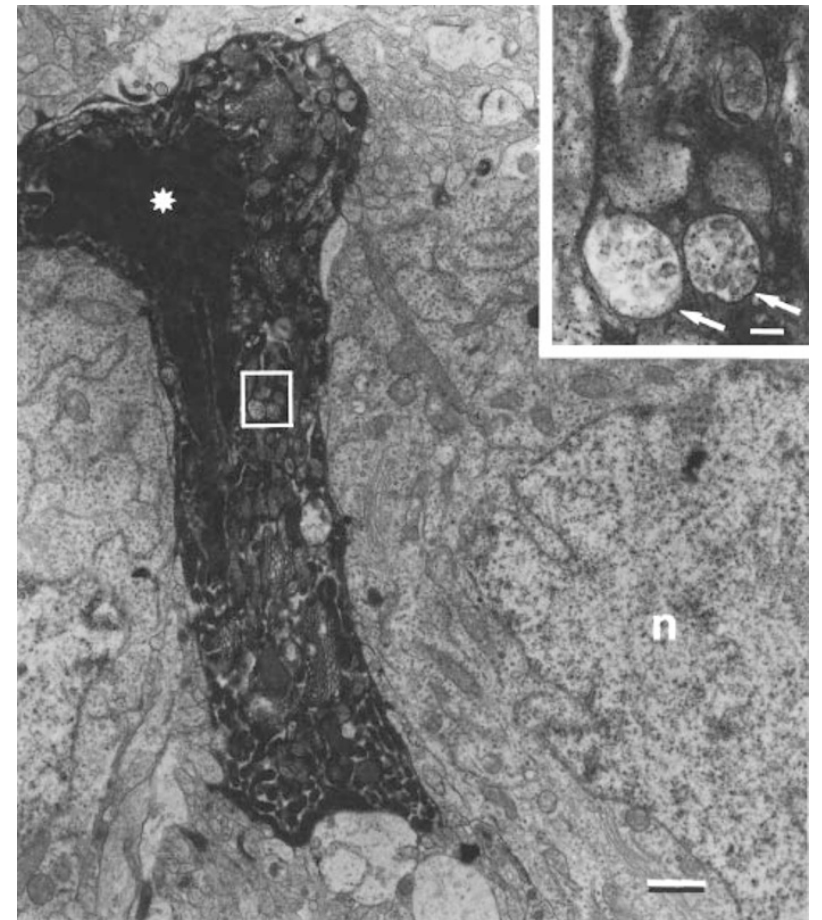

Figure 3 Virus replication is concomitant with apoptosis following infection of neural cells in vivo. Neonatal (P4 at infection) mouse brains were fixed and processed for transmission electron microscopy $36 \mathrm{~h}$ after intranasal SFV infection with 5000 PFU of SFV A7(74). Microscopic analysis revealed areas of extensive cellular pathology. Many cells were visible as electron dense profiles with shrunken, irregular shaped nuclei (asterisk) a morphology consistent with death by apoptosis. A normal nucleus ( $n$ ) of an adjacent cell is indicated for comparison. The vesiculated cytoplasm is indicative of infection and high resolution analysis of the cytoplasmic vesicles (magnified inset of area in white box) revealed membrane bound vesicles (arrows) containing structures typical of virus replication. These have been described previously as cytopathic vacuoles (Pathak and Webb 1978). Scale bars: $1 \mu \mathrm{m}$ and in inset $0.1 \mu \mathrm{m}$

widespread destruction of cells in the olfactory bulb in the CNS with a vast majority of the dying cells labelling with the TUNEL reaction (Figure $4 \mathrm{C}$; blue stain). Interspersed among the TUNEL positive cells were individual, or foci of, SFV infected cells (Figure 4C; brown stain). Occasionally, a few cells possessing a TUNEL positive nucleus (blue) and virus positive cytoplasm (brown) could be observed (arrowheads Figure 4C) suggesting that DNA fragmentation can coincide with infection, although the majority of cells show reciprocal staining patterns. No immunoreactivity for viral proteins and only the occasional TUNEL positive cell was observed in the corresponding olfactory bulb of age-matched (P4) uninfected mice (Figure 4C).

\section{Cysteine proteases function in apoptotic neurons}

As SFV infected cultures displayed not only the morphological characteristics, but also DNA fragmentation consistent with apoptosis we tested peptide inhibitors of caspases for their ability to suppress cell death following NGF withdrawal or infection. The modified peptide zVADfmk is a selective, membrane permeable, irreversible inhibitor of CED-3/ICE proteases. It has been shown to block thymocyte and monocyte apoptosis induced by etoposide, dexamethasone and staurosporine (Fearnhead et al, 1995; Zhu et al, 1995), cerebellar granule cell apoptosis induced by potassium ion/ serum withdrawal (Armstrong et al, 1997) and sympathetic neuron apoptosis induced by NGF deprivation (Deshmukh et al, 1996). The modified peptide Ac-DEVD-cho is considered a reversible inhibitor of CPP-32/apopain-like proteases and at relatively high (micromolar) concentrations has been shown to suppress apoptosis in intact cells (Nicholson et al, 1995; Schlegel, 1996). Initially, we tested these two reagents for their ability to suppress apoptosis of neurons induced by NGF deprivation. Both compounds were effective in a dose dependent manner when neurons were maintained in the absence of NGF for $48 \mathrm{~h}$ (Figure $5 \mathrm{~A}$ ). Both inhibitors were maximally effective at a concentration of $10^{-4}$ molar. The inhibitor Ac-DEVD-cho is clearly more potent than zVADfmk, supporting the survival of more than $80 \%$ of those neurons that would normally die in the absence of NGF. Suppression of apoptosis was not complete though, in that the majority of the treated neurons died by $96 \mathrm{~h}$. No survival promotion was observed at concentrations of either inhibitor lower than $10^{-6}$ molar, nor for vehicle treatment alone nor was there any significant increase in survival in cultures treated with the control aldehyde and ketone peptides leupeptin (Ac-LLRaldehyde) and $\mathrm{N}$-tosyl-lysine chloro methyl ketone (TLCK) at $10^{-4}$ molar. TLCK is a membrane permeable compound that can inhibit serine and non-ICE like cysteine proteases.

Although Ac-DEVD-cho is apparently the most effective of the two inhibitors in promoting the survival of neurons in the absence of NGF alone, it is ineffective at suppressing death induced by SFV infection (Figure 5B). At equivalent concentrations of $10^{-4}$ molar neither Ac-DEVD-cho, nor the control peptide leupeptin had any statistically significant effect on the number of surviving neurons at $48 \mathrm{~h}$ compared with those infected cells growing in the continued presence of NGF and given vehicle only. No death suppressing effect was observed for cells treated with aldehyde peptides or vehicle only, despite replenishment of the cells with fresh culture medium containing peptides every $24 \mathrm{~h}$. However, the percentage of cell death induced by virus after $48 \mathrm{~h}$ was abrogated following treatment of neurons with $10^{-4}$ molar zVADfmk. A statistically significant proportion of these treated neurons withstood the effects of the virus when compared with nonpeptide or vehicle treated neurons (One Way ANOVA; $P=<0.001$ ). At $48 \mathrm{~h}$ approximately $20 \%$ more neurons survived in the presence of zVADfmk, than in the presence of the control TLCK peptide.

\section{Discussion}

\section{Neurons apoptose in response to viral infection}

Using a patho-physiologically appropriate cell in tissue culture we have analyzed the cytopathology of alphavirus infection. We have used low density, dissociated cultures of embryonic mouse sensory neurons which are post-mitotic, have a 

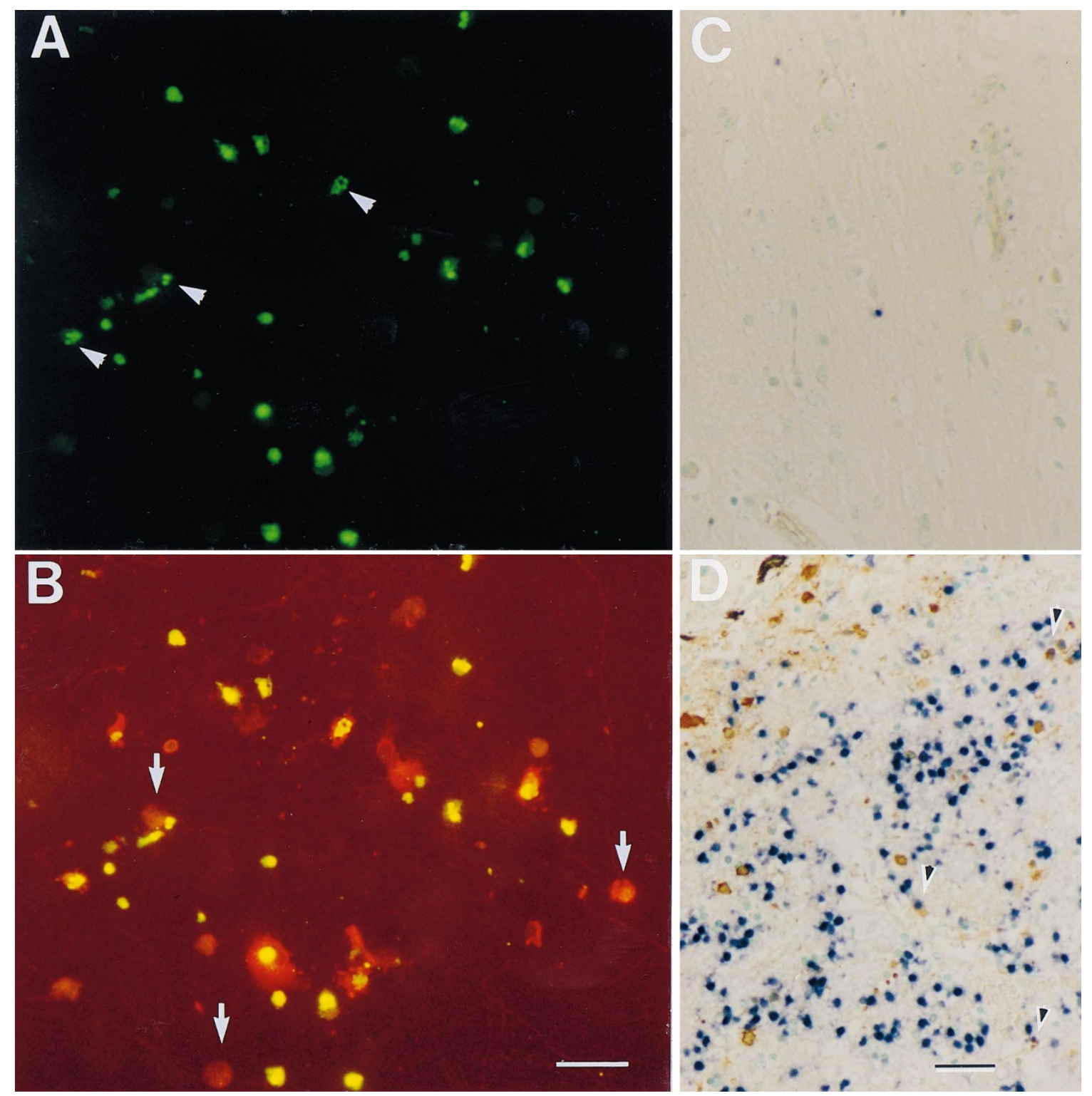

Figure 4 Neurons apoptosing as a result of infection undergo DNA fragmentation detectable by terminal transferase dUTP nick end labelling (TUNEL). Neurons in vitro (A and $\mathbf{B})$ were infected $(\mathrm{MOI}=5)$ and $30 \mathrm{~h}$ later fixed and processed for TUNEL and anti-neurofilament immunostaining. Many TUNEL-reactive nuclei were visible (green), some fragmented into TUNEL-reactive micronuclei (A; arrowheads). Immunostaining for neurofilament protein clearly indicated that some of the TUNEL-reactive nuclei belonged to neurons (red; B). However, not all neurons were TUNEL-reactive (B; arrows). Scale bar=50 $\mu \mathrm{ms}$. When neonatal mice were inoculated intranasally with SFV (as detailed in Figure 3), foci of SFV immunoreactivity coincided with TUNEL-reactivity in the olfactory bulb (D). In infected animals areas of extensive cytopathology consisted of TUNEL-reactive cells (blue nuclei), a few were also SFV immunoreactive (brown cytoplasm) (arrowheads; D). In control, uninfected age-matched neonatal mice there were only a few isolated TUNEL-reactive cells and no SFV immunoreactivity (C). Sections were counterstained with methyl green

neuronal morphology in culture, undergo a program of apoptosis following withdrawal of NGF and therefore can act as a sensitive, comparative indicator of the type of death induced by a virus. The dissociated primary cultures were devoid of, or contained only a low percentage of, nonneuronal cells minimising the potential action of paracrine toxic factors released by infected satellite cells. These neuronal cultures supported a productive infection with SFV and died with biochemical and morphological features of apoptosis. Apoptosis concurrent with a productive SFV infection was also observed for brain cells in neonatal mice. Infected neurons in culture died despite the presence of NGF, a soluble factor necessary and sufficient to suppress naturally-occurring cell death by apoptosis in greater than $60 \%$ of the cells. By assessing the number of surviving neurons over time, apoptosis occurred initially faster following NGF deprivation compared with virus infection. This was probably a reflection of the time required by the cells to initiate apoptosis in response to virus infection/replication, compared with the timing required following NGF deprivation. 

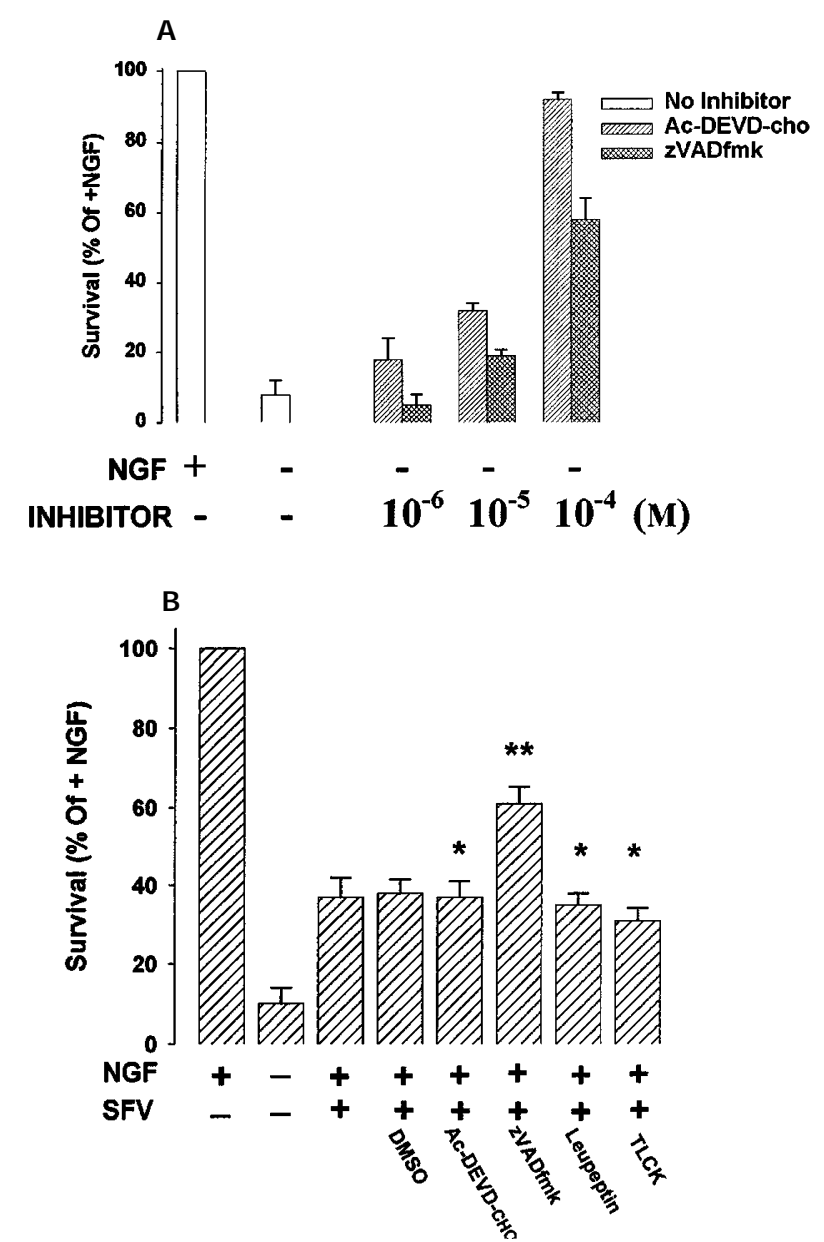

Figure 5 Neuronal apoptosis can be suppressed with caspase peptide inhibitors. (A) Low density cultures were either grown with NGF, or grown initially with NGF and then deprived (white bars). At the time of deprivation neurons received either no additive, or the indicated concentrations of peptide inhibitor (Ac-DEVDcho (slash bars); zVADfmk (check bars)). After $48 \mathrm{~h}$ the number of viable neurons was counted and the counts expressed as a percentage of the maximum number of neurons surviving in the presence of NGF alone. Data presented is the mean ( + S.D.) from 2 experiments $(n=12)$. (B) Neurons grown in the presence of NGF were either deprived of NGF or infected with SFV A7(74) (MOI=5). Two hours after infection, neurons were given the indicated peptides $\left(10^{-4} \mathrm{M}\right)$ or DMSO only and after a further $48 \mathrm{~h}$ the number of viable neurons was counted and counts expressed as a percentage of those obtained from neurons maintained by NGF alone. $\left(^{* *}\right)$ statistically significant difference (One Way ANOVA $P<0.001),\left({ }^{*}\right)$ no statistically significant difference from DMSO treated cultures). Abbreviations: DMSO, dimethyl sulphoxide; Ac-DEVD-cho, Ac-Asp-Glu-Val-Aspaldehyde; zVADfmk, benzyloxycarbonyl-Val-Ala-Asp-fluoromethylketone; leupeptin, Ac-Leu-Leu-Arg-aldehyde; TLCK, N-tosyl-lysine chloromethylketone

In addition to the morphological changes we employed two biochemical criteria to analyze virus-induced apoptosis; detection of DNA breaks in dying cells using the TUNEL method and sensitivity of the cell death process to peptide inhibitors of caspases. The use of terminal transferase (TdT) to incorporate labelled nucleotides into DNA fragments has been much favoured since its proposal as a convenient method to detect apoptotic cells in situ (Gavrieli et al, 1992). However, a more recent and stringent analysis of the type of DNA cleavage occurring specifically in apoptotic cells (Didenko and Hornsby, 1996) has indicated that the enzyme TdT will not distinguish between the type of DNA fragmentation observed in apoptotic cells from that observed in response to a range of conditions, including that typical of necrosis in situ. Our observations indicated that nuclear DNA fragmentation (TUNEL reactivity) occurred prior to the morphological changes of death in tissue culture and that TUNEL reactive neuronal nuclei possessed an apoptotic morphology (labelled chromatin aggregates and formation of micronuclei). This would be consistent with virus-induced apoptosis rather than necrosis, when DNA degradation is thought to be a very late event (Majno and Joris, 1995). It was difficult to resolve TUNEL-labelled apoptotic nuclear changes in tissue sections taken from the brains of infected neonatal mice. However, ultrastructural analysis of infected dying neural cells in vivo was clearly indicative of apoptosis. This observation in combination with TUNEL and antiSFV immunocytochemistry suggests that apoptosis is an important mechanism of cell death following infection of neonatal neurons.

The rate of neuronal apoptosis induced by either SFV infection or NGF deprivation in vitro could be abrogated using caspase inhibitors, in particular both types of death event were sensitive to the irreversible CED-3/ICE caspase inhibitor zVADfmk. Interestingly, the somas of NGFdeprived neurons exposed to inhibitors no longer retained a phase-bright, spherical appearance. The cytoplasm of these cells became granular and the soma shape irregular (data not shown). This suggests that not all the morphological changes of apoptosis can be suppressed using peptide inhibitors. The reversible inhibitor Ac-DEVDcho was clearly more potent than zVADfmk in promoting survival in the absence of NGF. There is some debate as to how effective aldehyde modified peptides are in whole cell experiments due to their limited membrane penetrance. The high (micromolar) concentrations required in our assays is similar to the concentration of Ac-DEVD-cho used by others to inhibit CPP32/apopain and apoptosis in intact cells (Nicholson et al, 1995; Schlegel et al, 1996) but is far in excess of the $\mathrm{IC}_{50}$ for isolated CPP32/apopain (0.2 nM). Uptake of Ac-DEVD-cho by cells in our experiments may have been facilitated by the high degree of pinocytosis and membrane recycling known to occur when embryonic neurons grow rapidly in the presence of NGF. As AcDEVD-cho can promote survival of neurons this implies that possibly a caspase of the CPP-32-like subfamily is activated following NGF withdrawal. Activation of one or more caspases following NGF withdrawal is consistent with previous findings by others that over-expression of the viral caspase inhibitors crmA or p35 in neurons, or the use of peptide inhibitors on trophic factor deprived neurons promotes their survival in culture (Gagliardini et al, 1994; Milligan et al, 1995; Martinou et al, 1995; Troy et al, 1996; Sadoul et al, 1996). So far however, no experiments have allowed the precise identification of the caspases required for neuronal death triggered by deprivation from trophic support. 
Infection-induced neuronal apoptosis is, at least in some cells, sensitive to the inhibitor zVADfmk and although we cannot formally rule out the possibility that this peptide but not the control peptide specifically interferes with virus replication, this would seem unlikely and we infer that activation of one or more caspases occurs in infected cells even in the presence of NGF. This would suggest that the signals generated by NGF exposure to maintain viability by preventing caspase activation are circumvented or overridden by death-inducing signals associated with virus infection/replication. Alternatively, virus-induced death may require a zVADfmk-sensitive caspase that is insensitive to the modulating activity of NGF. Activation of a CPP-32/ apopain-like caspase following Sindbis virus infection has been inferred from observations of poly (ADP-ribose) polymerase (PARP) cleavage in neuroblastoma cells (Ubol et al, 1996). We failed to detect any activity for AcDEVD-cho in inhibiting virus-induced neuronal apoptosis. This could also be considered as indirect evidence for the existence or activation of caspases insensitive to the action of NGF but specific to virus infection, or merely reflect an inability of the aldehyde inhibitor to delay the cell death efficiently enough. This could conceivably be the case as infected neurons maintained by zVADfmk do eventually die. Our observations derived from the use of these inhibitors constitute the first indication of a requirement for a caspase in virus-induced death of appropriate post-mitotic neurons.

\section{Cellular changes associated with virus-induced apoptosis}

Previous studies using alphavirus infection of various cell lines have implicated a number of biochemical events that occur prior to or concomitant with apoptosis. A reduction in proliferative capacity caused by over-expression of dominant negative ras (Ha-ras (Asn17)) in the pheochromacytoma cell line, PC12, suppresses but does not totally inhibit apoptosis induced by Sindbis virus infection (Joe et al, 1996). Apoptosis of proliferating N18 neuroblastoma cells due to Sindbis virus was shown to involve initial activation of the DNA repair enzyme PARP along with the transcription factor NF-kappa B (Lin et al, 1995; Ubol et al, 1996). Using oligonucleotide decoys for NF-kappa B, changes in activity of this transcription factor were also shown to be necessary for apoptosis of AT-3 (adenocarcinoma), but not N18 cells following Sindbis virus infection, suggesting a cell-type specific signal cascade leading to apoptosis regulation. Activation of NF-kappa B apart, none of these changes observed in cell lines have been shown to be sufficient for death induction by viruses.

How the cell is able to detect and respond to the stress of alphavirus infection by engaging the mechanism leading to apoptosis is not known. For large DNA viruses such as baculovirus and adenovirus, there have been identified specific, early-expressed viral genes which cause apoptosis as a result of forcing cells into a proliferative state (Prikhod'ko and Miller, 1996; White, 1996). Of the four non-structural and four structural gene products of alphaviruses none as yet, either singly or collectively have been shown to possess any anti- or pro-apoptotic side effects. Studies on Sindbis and baculovirus have suggested that there is a major requirement for viral replication in order to trigger host cell apoptosis (Ubol et al, 1996; LaCount and Friesen, 1997). This is consistent with our observation on infected neurons showing that following exposure to virus there is a delay in cell death relative to that seen for NGF withdrawal. This presumably results from a requirement for viral replication before apoptosis is triggered.

The aptness of observations derived from studies of continuous cell lines in culture to biochemical events regulating apoptosis in post-mitotic neurons is not clear as the cell cycle regulatory components, transcription factors, bcl-2 and caspase family members in proliferating cells are different from those in fully differentiated cells. A detailed characterisation of these differences in neurons is necessary in order to understand how a virus, such as SFV, can induce apoptosis. This is essential as neurons of the mature nervous system are not generally replaceable should they die due to infection. Such studies will be facilitated, as described here using primary cultures of neurons at appropriate stages of differentiation.

\section{Materials and Methods}

\section{Neuronal cell culture}

Mouse embryos were removed from time mated pregnant females and staged as embryonic day 14 (E14) according to the criteria of Theiler (1972). At this stage in vivo trigeminal sensory neurons are undergoing naturally-occurring cell death which is suppressed by target-derived NGF. Ganglia were aseptically dissected using sharpened tungsten needles and incubated for $7 \mathrm{~min}$ at $37^{\circ} \mathrm{C}$ with $0.05 \%$ trypsin (Worthington) in calcium/magnesium-free Hanks balanced salt solution (HBSS). After removal of the trypsin solution, the ganglia were washed once with $5 \mathrm{mls}$ of Ham's F12 medium containing $5 \%$ heat-inactivated horse serum and gently titrated with a fire-polished, siliconised Pasteur pipette to yield a single cell suspension. Cells were plated at a density of 300-700 neurons per $35 \mathrm{~mm}$ diameter tissue culture dish (NUNC). Dishes had been previously coated with polyornithine $(0.5 \mathrm{mg} / \mathrm{ml})$ and laminin $(20 \mu \mathrm{g} /$ $\mathrm{ml}$ ). Neurons were grown (at $37^{\circ} \mathrm{C} ; 5 \% \mathrm{CO}_{2}$ ) in serum-free medium consisting of Ham's F14 supplemented with $2 \mathrm{mM}$ glutamine, $0.35 \%$ BSA (Pathocyte-4, ICN), $60 \mathrm{ng} / \mathrm{ml}$ progesterone, $16 \mu \mathrm{g} / \mathrm{ml}$ putrescine, $400 \mathrm{ng} / \mathrm{ml}$ L-thyroxine, $38 \mathrm{ng} / \mathrm{ml}$ sodium selenite, $340 \mathrm{ng} / \mathrm{ml}$ triiodothyronine, $60 \mathrm{mg} / \mathrm{ml}$ penicillin, $100 \mathrm{mg} / \mathrm{ml}$ streptomycin, $4 \mathrm{ng} / \mathrm{ml}$ recombinant human NGF (R\&D Systems). This medium was not conducive to the proliferation and survival of non-neuronal cells, with the result that over $90 \%$ of the cells in these cultures were neurons. After overnight growth the number of attached neurons within a $12 \times 12 \mathrm{~mm}$ square in the centre of each dish was counted and the mean of these counts taken as the initial number of neurons at the start of the experiment.

\section{Viruses and plaque assays}

The A7(74) and L10 strains of SFV were purified on sucrose gradients and by precipitation to remove any growth factors or inhibitors and titred using plaque assays on $80 \%$ confluent BHK cells as previously described (Fazakerley et al, 1993; Scallan et al, 1997). 


\section{Apoptotic assays}

Neurons were induced to die either by withdrawal of NGF or infection with SFV. The estimates of plating density were used to calculate the amount of virus stock required to give the final $\mathrm{MOI}$. All neurons were initially washed with NGF-free growth medium and then either grown continuously with re-supplemented NGF $(4 \mathrm{ng} / \mathrm{ml})$, grown with NGF but infected with purified SFV of either the A7(74) or L10 strains, or grown without NGF. For estimates of cell viability, the number of cells remaining in the same $12 \times 12 \mathrm{~mm}$ square was counted every $24 \mathrm{~h}$ and the results expressed as a percentage of the initial number of attached neurons. Neurons were considered viable if they possessed a phasebright soma and intact neurites of length greater than two times the diameter of the soma. In each experiment quadruplet cultures were set up for all experimental conditions. For time lapsed analysis of morphological changes, culture dishes were filled with $5 \%$ carbon dioxide saturated growth medium and the lids sealed with silicon grease (Dow Corning). Care was taken to exclude all air bubbles. Dishes were then incubated $\left(37^{\circ} \mathrm{C}\right)$ on a heated microscope headstage and defined neurons were photographed using $35 \mathrm{~mm}$ film (rated 100 ASA).

\section{Peptide inhibitor assays}

Stock solutions of modified peptides were prepared in DMSO (10 mM) and stored at $-20^{\circ} \mathrm{C}$. Neurons were triggered to die by NGF deprivation or SFV infection as described except that replacement medium contained the required dilute concentrations of peptide or vehicle only as control. Neurons exposed to the A7(74) strain of SFV were given a lag period of $2 \mathrm{~h}$ before addition of peptide, in order not to interfere with the infection process. Medium was exchanged every $24 \mathrm{~h}$ for fresh medium containing peptides and the number of viable neurons remaining after $48 \mathrm{~h}$ was counted using the criteria described previously. Results were expressed as a percentage of the maximum number of surviving neurons maintained with NGF alone for $48 \mathrm{~h}$. In each experiment quadruplet cultures were set up for all experimental conditions.

\section{Electron microscopy}

Neurons were grown on laminin-coated Thermanox plastic coverslips. Approximately $36 \mathrm{~h}$ after being induced to die by either SFV infection or NGF withdrawal the cultures were washed briefly with warm cacodylate buffer $(0.1 \mathrm{M} ; \mathrm{pH} 7.4)$ and then fixed with $3 \%$ glutaraldehyde (cacodylate buffer $\mathrm{pH} 7.4$ ) for $3 \mathrm{~h}$. Cultures were subsequently post-fixed ( $1 \%$ osmium tetroxide, cacodylate buffer), washed and dehydrated using graded acetones. Following critical point drying and sputter coating, samples were analyzed using a Philips 505 scanning electron microscope. Brain samples from infected neonatal mice were fixed, post-fixed and dehydrated as described above. Samples were then infiltrated and embedded with Araldite $\left(48 \mathrm{~h}\right.$ at $\left.60^{\circ} \mathrm{C}\right)$, sectioned and mounted on 200 mesh copper grids. Sections were finally stained with uranyl acetate/lead citrate and viewed using a Philips 400 transmission electron microscope.

\section{Immunofluorescence}

Neurons were identified using the RT-97 monoclonal antibody which recognises phosphorylated neurofilaments (gift from Peter Mulderry, University of Edinburgh). Viral glycoproteins were detected using antipeptide antisera (raised in rabbits) specific for SFV E1 and E2. Cultures were grown in $35 \mathrm{~mm}$ diameter dishes, rinsed with warm phosphate buffered saline (PBS) and fixed with $4 \%$ formaldehyde in
(PBS). Cells were permeabilised $(0.3 \%$ Triton X-100) and incubated with either the RT-97 monoclonal antibody $(1: 1000)$ or the anti-SFV antisera $(1: 500)$ alone, or with these two reagents combined. After washing, bound antibodies were sequentially detected using fluorescein isothiocyanate (FITC)-conjugated goat anti-rabbit antibodies (Dako) and rhodamine isothiocyanate (RITC)-conjugated goat anti-mouse antibodies. All antibodies were diluted in $1 \%$ normal goat serum in PBS.

\section{TUNEL}

Infected neurons were rinsed with warm PBS and fixed with $2 \%$ paraformaldehyde-lysine-periodate (PLP) fixative. After permeabilisation the preparations were first equilibrated with TUNEL buffer $(30 \mathrm{mM}$ Tris- $\mathrm{HCl} \mathrm{pH} \mathrm{7.2,} 140 \mathrm{mM}$ sodium cacodylate, $1 \mathrm{mM}$ cobalt chloride) for $15 \mathrm{~min}$ and then incubated with terminal transferase (TdT, $0.6 \mathrm{U} / \mu \mathrm{l}$, Promega) and DIG-11-dUTP $(20 \mu \mathrm{M}$, Boehringer Mannheim) in TUNEL buffer for $2 \mathrm{~h}$ at $37^{\circ} \mathrm{C}$. As a control TdT was omitted from one enzyme reaction. The enzyme reaction was terminated by rinsing with $2 \times$ SSC ( $300 \mathrm{mM}$ sodium chloride, $300 \mathrm{mM}$ sodium citrate). Cultures were then equilibrated with PBS and incorporated DIG-dUTP was detected using FITC-conjugated anti-DIG antibody $(1: 100$; Boehringer Mannheim) diluted in PBS containing 1\% goat serum. To assess the efficacy of the terminal transferase in every experiment, a dish containing viable, uninfected neurons was treated to artificially introduce nuclear DNA breaks. Cells were fixed/permeabilised and first equilibrated in DNase 1 buffer ( $30 \mathrm{mM}$ Tris- $\mathrm{HCl} \mathrm{pH} \mathrm{7.2,140} \mathrm{mM}$ sodium cacodylate, $4 \mathrm{mM}$ magnesium chloride, $0.1 \mathrm{mM}$ dithiothreitol) followed by incubation with DNase $1(5 \mu \mathrm{g} / \mathrm{ml})$ in this buffer at $37^{\circ} \mathrm{C}$ for $30 \mathrm{~min}$. Cells were then rinsed and prepared for TUNEL. Different fixation procedures were used on uninfected control cells in order to determine whether artifactual DNA breaks are introduced by processing. These additional tests gave no labelling with the TUNEL reaction.

\section{Acknowledgements}

We thank Yvonne Trozer, Sylvia Shaw, Steve Mitchell for expert technical assistance and Dr Peter Mulderry (MRC Brain Metabolism Unit, University of Edinburgh) for the RT-97 antibody. This work was supported by grants from the Medical Research Council and the Multiple Sclerosis Society.

\section{References}

Allsopp TE, Wyatt S, Paterson HF and Davies AM (1993) The proto-oncogene bcl-2 can selectively rescue neurotrophic factor-dependent neurons from apoptosis. Cell 73: 295-307

Armstrong RC, Aja TJ, Hoang KD, Gaur S, Bai X, Alnemri ES, Litwack G, Karanewsky DS, Fritz LC and Tomaselli KJ (1997) Activation of the Ced3/ICE-related protease CPP32 in cerebellar granule neurons undergoing apoptosis but not necrosis. J. Neuroscience 15: 553-562

Bertin J, Armstrong RC, Ottilie S, Martin DA, Wang Y, Banks S, Wang GH, Senkevich TG, Alnemri ES, Moss B, Lenardo MJ, Tomaselli KJ and Cohen JI (1997) Death effector domain-containing herpesvirus and poxvirus proteins inhibit both Fasand TNFR-1-induced apoptosis. Proc. Natl. Acad. Sci. USA 94: 1172-1176

Clem RJ, Fechheimer M and Miller LK (1991) Prevention of apoptosis by a baculovirus gene during infection of insect cells. Science 254: 1388-1390

Despres P, Flamand M, Ceccaldi P-Eand DeubelV (1996) Human isolates of Dengue Type 1 virus induce apoptosis in mouse neuroblastoma cells. J. Virology 70 : 4090-4096

Deshmukh M, Vasilakos J, Deckworth TL, Lampe PA, Shivers BD and Johnson JrEM (1996) Genetic and metabolic status of NGF deprived sympathetic neurons saved by an inhibitor of ICE family proteases. J. Cell Biol. 135: 1341-1354 
Didenko VV and Hornsby PJ (1996) Presence of double strand breaks with single base $3^{\prime}$ overhangs in cells undergoing apoptosis but not necrosis. J. Cell Biol. 135: $1369-1376$

Fazakerley JK and Webb HE (1987) Semliki Forest virus induced, immune mediated demyelination: the effect of irradiation. Br. J. Exp. Pathol. 68: 101-113

Fazakerley JK, Pathak S, Scallan M, Amor S and Dyson H (1993) Replication of the A7(74) strain of Semliki Forest virus is restricted in neurons. Virology 195: 627 637

Fearnhead HO, Dinsdale D and Cohen GM (1995) An interleukin-1-beta converting enzyme-like protease is a common mediator of apoptosis in thymocytes. FEBS Lett. 375: 283-288

Gagliardini V, Fernandez P-A, Lee RKK, Drexler HCA, Rotello RJ, Fishman MC and Yuan J (1994) Prevention of vertebrate neuronal death by the crmA gene. Science 263: 826-828

Gavrieli Y, Sherman Y and Ben-Sasson SA (1992) Identification of programmed cell death in situ via specific labelling of nuclear DNA fragmentation. J. Cell Biol. 119: 493-501

Gillet $\mathrm{G}$ and Brun $\mathrm{G}$ (1996) Viral inhibition of apoptosis. Trends in Microbiology 4 312-317

Joe AK, Ferrari G, Jiang HH, Liang XH and Levine B (1996) Dominant inhibitory ras delays Sindbis virus-induced apoptosis in neuronal cells. J. Virology 70: 7744 7751

Kiefer MC, BrauerMJ, Powers VC, Wu JJ, Umansky SR, TomeiLD and BarrPJ (1995) Modulation of apoptosis by the widely distributed bcl-2 homologue bak. Nature 374: $736-739$

LaCount DJ and Friesen PD (1997) Role of early and late replication events in induction of apoptosis by baculoviruses. J. Virology 71: 1530-1537

Levine B, Huang Q, Isaacs JT, Reed JC, Griffin DE and Hardwick JM (1993) Conversion of lytic to persistent alphavirus infection by the bcl-2 cellular oncogene. Nature 361: 739-742

Lewis J, Wesselingh SL, Griffin DE and Hardwick JM (1996) Alphavirus-induced apoptosis in mouse brains correlates with neurovirulence. J. Virology 70: 1828 1835

Lin KI, Lee SH, Narayanan R, Baraban JM, Hardwick JM and Ratan RJ (1995) Thio agents and bcl-2 identify an alphavirus-induced apoptotic pathway that requires activation of the transcription factor NF-kappa B. J. Cell Biol. 131: 1149-1161

Majno $G$ and Joris I (1995) Apoptosis, oncosis and necrosis. An overview of cell death. Am. J. Pathology 146: 3-15

Martinou I, Fernandez P-A, Missotten M, White E, Allet B, Sadoul R and Martinou J-C (1995) Viral proteins E1B-19k and p35 protect sympathetic neurons from cell death induced by NGF deprivation. J. Cell Biol. 128: 201-208

Milligan CE, Prevette D, Yaginuma H, Homma S, Cardwell C, Fritz LC, Tomaselli KJ, Oppenheim RW and Schwartz LM (1995) Peptide Inhibitors of the ICE protease family arrest programmed cell death of motoneurons in vivo and in vitro. Neuron 15: $385-393$

Nicholson DW, Ali A, Thornberry NA, Vaillancourt JP, Ding CK, Gallant M, Gareau Y, Griffin PR, Labelle M, Lazebnik YA, Munday NA, Raju SM, Smulson ME, Yamin TT, Yu VL and Miller DK (1995) Identification and inhibition of the ICE/CED-3 protease necessary for mammalian apoptosis. Nature 376: 37-43

Oliver KR, Scallan MF, Dyson H and Fazakerley JK (1997) Susceptibility to a neurotropic virus and its changing distribution in the developing brain is a function of CNS maturity. J. Neurovirol. 3: 38-48

Oltvai ZN, Millman CL and Korsmeyer SJ (1993) Bcl-2 heterodimerises in vivo with a conserved homolog, bax, that accelerates programmed cell death. Cell 74:609 619
Pathak S and Webb HE (1978) An electron-microscope study of avirulent and virulent Semliki Forest virus in the brains of different ages of mice. J. Neurol. Sci. 39: 199-211

Peitsch MC, Mannherz HG and Tschopp J (1994) The apoptosis endonucleases: cleaning up after cell death? Trends in Cell Biology 4: 37-41

Pekosz A, Phillips J, Pleasure D, Merry D and Gonzalez-Scarano F (1996) Induction of apoptosis by La Crosse virus infection and role of neuronal differentiation and human bcl-2 expression in its prevention. J. Virology 70: 5329-5335

Prikhod'ko EA and Miller LK (1996) Induction of apoptosis by baculovirus transactivator IE1. J. Virology 70: 7116-7124

Rao L, Debbas M, Sabbatini P, Hockenbery D, Korsmeyer S and White E (1992) The adenovirus E1-A proteins induce apoptosis which is inhibited by the E1B 19Kda and bcl-2 proteins. Proc. Natl. Acad. Sci. USA 89: 7742-7746

Sadoul R, Fernandez P-A, Quiquerez A-L, Martinou I, Maki M, Schroter M, Becherer JD, Irmler M, Tschopp J and Martinou J-C (1996) Involvement of the proteosome in the programmed cell death of NGF-deprived sympathetic neurons. EMBO J. 15: $3845-3852$

Scallan MF, Allsopp TE and Fazakerley (1997) Bcl-2 acts early to restrict Semliki Forest virus replication and delays virus induced programmed cell death. $J$. Virology 71: 1583-1590

Schlegel J, Peters I, Orenius S, Miller DK, Thornberry NA, Yamin TT and Nicholson DW (1996) CPP32/apopain is a key interleukin-1-beta converting enzyme like protease in Fas mediated apoptosis. J. Bio. Chem. 271: 1841-1844

Sharpe AH, Hunter JJ, Chassler P and Jaenisch R (1990) Role of abortive retroviral infection of neurons in spongiform CNS degeneration. Nature 346: 181-183

StellerH(1995) Mechanisms and genes of cellular suicide. Science 267: 1445-1449

Strack PR, Frey MW, Rizzo CJ, Cordova B, George HJ, Meade R, Ho SP, Corman J, Tritch R and Korant BD (1996) Apoptosis mediated by HIV protease is preceded by cleavage of Bcl-2. Proc. Natl. Acad. Sci. USA 93: 9571-9576

Swoveland PT and Johnson KP (1989) Host age and cell type influence measles virus protein expression in the central nervous system. Virology 170: 131-138

Theiler K (1972) The house mouse (development and normal stages from fertilization to 4 weeks) Berlin: Springer

Thome M, Schneider P, Hofmann K, Fickenscher H, Meini E, Neipel F, Mattmann C Burns K, Bodmer JL, Schroter M, Scaffidi C, KrammerPH, Peter ME and Tschopp $\mathrm{J}$ (1997) Viral FLICE-inhibitory proteins (FLIPs) prevent apoptosis induced by death receptors. Nature 386: 517-521

Thompson CB (1995) Apoptosis in the pathogenesis and treatment of disease. Science 267: $1456-1462$

Troy CM, Stefanis L, Prochiantz A, Greene LA and Shelanski ML (1995) The contrasting roles of ICE family proteases and IL-1 $\beta$ in apoptosis induced by trophic factor withdrawal and by copper/zinc superoxide dismutase downregulation. Proc. Natl. Acad. Sci. USA 93: 5635-5640

Ubol S, Park S, Budihardjo I, Desnoyers S, Montrose MH, Poirier GG, Kaufmann SH and Griffin DE (1996) Temporal changes in chromatin, intracellular calcium, and poly (ADP-ribose) polymerase during Sindbis virus-induced apoptosis of neuroblastoma cells. J. Virology 70: $2215-2220$

White $E$ (1996) Life, Death, and the pursuit of apoptosis. Genes \& Development 10 $1-15$

Zhu HJ, Fearnhead HO and Cohen GM (1995) An ICE-like protease is a common mediator of apoptosis induced by diverse stimuli in human monocytic THP.1 cells. FEBS Lett. 374: 303-308 